Migration Studies - Review of Polish Diaspora nr 3 (177)/2020, http://www.ejournals.eu/Studia-Migracyjne/ DOI: 10.4467/25444972SMPP.20.035.12599

\title{
The Syrian Post-revolutionary Art: The Lingua Franca of the EU
}

\author{
KSENIA PROSYUKOVA 1 \\ ORCID: 0000-0002-8567-4658 \\ Institute of International Relations \\ Kazan Federal University
}

The Syrian political crisis that swept through the country caused a fierce, exhausting, destructive war and forced hundreds of thousands of Syrians to leave their homes in search of a safe life, though full of deprivation. Many of them have settled in the EU. According to psychologists, the level of stress that a person experiences during the process of adaptation to a new environment and integration into a new society is enormous and equal to 8 (on a scale from 1 to 10), which certainly affects many aspects of life, including the artistic potential. The aim of this study is to analyze the art of the Syrian descendants which is currently becoming a new way of communication and helps to discuss problems in those fields where the artistic expression is more effective than the verbal means of communication.

Keywords: Syrian refugees, migration crisis, Syrian refugee art, Syrian art, Syrian Arab Republic

\section{Introduction}

The political conflict that started in Syria in 2011 and has not ceased yet, is one of the key agendas of any media so far: first we got information on military campaigns in Syria, now - news from the EU countries, where refugees from Syria headed for in search of security, opportunities for personal development, a better future for their children. And while political scientists, economists and sociologists are trying to predict the outcome and results of this migration movement, as well as find ways to resolve the most global migration crisis in the contemporary history, we, education experts, are more focused on other aspects: how refugees can effectively and painlessly get adapted to a new educational environment; what can help to integrate the bearers

1 Contact: prokseniya@mail.ru 
of a radically different culture into the European society; whether and how, if necessary, we can change the education system in the EU so the refugees get educational opportunities, become active participants of the society, get a chance to develop their abilities, be able to overcome the cultural shock and a language barrier. Also, one of the major aims is to create opportunities to unlock and develop the creative potential of Syrian refugees. To be creative is one of the key needs of an individual; to a lesser extent it depends on those competencies and skills formed by the traditional system of education. And, consequently, to a greater extent it is formed and developed within the process of interaction with other members of society; under the influence of internal and external transformations of the environment where an individual lives; as a result of radical changes in living conditions, stress, forced transformations.

The existence of migrant communities (ethnic, religious, cultural, etc.) is a fact, so the baseline for our discussion is more related to existence of a certain kind of space social, cultural, symbolic that unites people belonging to particular communities. In the process of such interaction they rethink their environment and themselves. By analyzing the selected materials - mainly interviews with representatives of the creative environment, originally from Syria, we came to the conclusion that artistic endeavour in Syria is censored, many topics are declared taboo, which in part has become a reason for many of them to seek asylum in a foreign land, where they can safely express their attitude to existing problems and convey their well-grounded views. Also, one of the most striking phenomena is the emergence of a new creative class, whose representatives were never (before migration) engaged in painting, musical arts or photography. All of them, as a rule, note that interaction with the new culture, new realities, life hardships (unsettled state, lack of knowledge of the language and inability to communicate in the new society, lack of demand as a specialist, deprivation, separation from the family, etc.) and the new experience they gained, contributed to the development of creativity and formation of a new point of view on the surrounding reality.

The key topic of this study is to analyze the forms of self-expression of migrants from Syria: what is expressed in the artistic work of Syrian migrants in the EU and what remains "hidden"; who is the intended recipient, the addressee of the cultural products produced by migrants; what forms the expression of migrant experience can have; what conclusions can be drawn from this analysis regarding the (re)configuration of the identities of migrants and the "host" society?

\section{Methodological Framework}

The first stage of the study is a sociological description based on the analysis of publicly available empirical data collected from social network groups (for example, Syria. Art on Facebook), videos on Youtube, interviews with Syrian artists, musicians and other representatives of the artistic environment. 


\section{SM̂PP}

At the second stage we formed a target group of 30 respondents - migrants from Syria who represent different fields and industries and live in Russia and the EU (Germany, Spain); students and unemployed; those who already have an official status and a labor permit or a student visa and those who are just awaiting the official status. The above-mentioned countries were selected as case-study material within the framework of the stated problem for a number of reasons:

- we aimed at presenting an analysis based on the case-study in countries that are culturally different from each other. Partly for this reason, having a wellformed research base (a group of respondents in each of these countries that previously participated in other studies mainly focused to assess the ability of national education systems to adapt to new social conditions (migratory influx)), we suggested that our present study can also be quite useful;

- these three countries faced a large flow of migrants from Syria. According to UNCHR statistics, Germany accepted the largest number of refugees from Syria in the EU $(532,000)$, whereas Spain is one of the EU littoral states, which was one of the first to face the flow of migrants, who then settled in other EU countries, without getting into the official statistics of those whom Spain hosted (officially Spain granted asylum to 28,300 refugees from Syria) (UNCHR data). Nevertheless, the period that refugees spend in refugee camps in Spain, waiting for further resettlement, became the first contact with a new culture and new society, which, of course, had a further impact on formation of their identity and the process of adaptation to new conditions. As for Russia, according to official statistics, the number of Syrian citizens who applied for asylum is relatively small - about 600 people, but the number of citizens from Syria who arrived in a different status (students who arrived under Russian cooperation programs with universities, grant-aided students; Syrian specialists with work permits; persons who received a residence permit in the Russian Federation due to family engagement, etc.) - more than 9,000 people (according to the Russian Migration Service official data), which in the context of Russia's rather conservative migration policy makes Syrians the second largest group of migrants after Ukrainians.

The aim of the study was to discuss the selected (by the method of continuous sampling in the category of visual arts) examples in an interview format. During the interview we asked a number of clearly defined questions in a given sequence: 1. What is the main theme of this work of art? 2. What was the artist's intention? 3. Does this topic resonate with the representatives of a host society? After the interview, the responses of the participants were evaluated by an expert group consisting of art historians, sociologists and psychologists. The respondents' responses were grouped based on matching / non-matching associations, which were subsequently summarized by the experts and presented as a total percentage of matches. At the third stage of the study, the research results were presented in the form of a detailed report. 


\section{Results}

\section{Transformation of the Public Sphere}

Within the previous stage of our complex study on adaptation and integration of Syrian migrants, we noted that such an active migration process not only causes transformations of the worldview of migrants - representatives of the alien culture, who have a different social experience formed in a different environment, who have different moral and aesthetic values; but the process can also have an impact on the worldview of the "host society" in response to the transformation of the familiar environment. A similar interdependent phenomenon has already been observed earlier - in the process of active migration of representatives from European and Asian countries to the territory of North America throughout the XX century. As a result of rethinking the changing conditions and introducing new elements of culture, several key trends in musical arts (but not only) were noted:

- formation of the reactionary art: emergence of new movements and their strengthening, the growing popularity of ethnical and cultural arts. For example, the popularity of "black" music - jazz at the beginning of the 20th century; rap and hip-hop in the second half of the 20th century right after the second wave of migration;

- the role of art as a mild form of protest movements: folk music as an attempt to draw the attention of the publicity to the problem of class solidarity and its connection with the "marginal" culture; country music as a form of protest against urbanization, refusal of "simple" values, transformation of the patriarchal social structure;

- the role of arts as a means of strengthening the dialogue among cultures: eclecticism in music and visual arts; an attempt to maintain the roots and express potential to assimilate and respect the traits of the "host" culture.

In the author's note to "The Structural Transformation of the Public Sphere: An Inquiry into a category of Bourgeois Society" Jurgen Habermas gives a point that he intentionally ignored any alternative to the object of his research which is the bourgeois society (Malakhov, Olimova, Simon 2019: 33). According to Habermas, the "host" culture always has a status of an "official", dominant, basic one. Any other cultural expressions that can be considered as alternatives to the bourgeois culture, he refers to the so-called "plebian" culture - culture for certain groups of people, which always was a "hidden" culture, and existed only for those who identified themselves as bearers of that culture (Habermas 1991: 175).

Habermas' theory has been criticized by numerous scholars: a British social scientist Paul Gilroy has repeatedly questioned the thesis on confrontation of the "bourgeois" culture with alternative movements (Malakhov, Olimova, Simon 2019: 37).

130 The "black culture" that has already been mentioned, was formed under the influence 


\section{SM̂PP}

of oppression resulted from the slave trade, but became a form of cultural modernism in the USA and originated an alternative social sphere that goes beyond the only African-American culture.

The same process can be traced in Europe where the products of a migrant culture (from Syria within the context of our research) are in demand not only among migrants - bearers of same aesthetic and moral values, same cultural experience, but among the members of the "host" culture as well, who feel interest in the alien culture and admit that getting closer to the migrants' arts helps to understand migrants better, perceive their way to express themselves and behave. Arts play the role of a "mediator" and an "advocate", as well as the lingua franca that helps to understand each other when the real language in common is absent.

\section{Syrian Art: the EU case-study}

As a result of the events of 2011, many representatives of the artistic environment from Syria decided to migrate to the EU countries. Some of them were able to get internships to study at the art academies in the EU countries, but faced with the problem of financing such internships. Taking into account the historical past and special relations between Syria and France that were established decades ago (Syria was one of French colonies), many of the migrants managed to get scholarships that covered their education in France. The Angela Merkel's open access policy also created fertile ground for Syrian artists and musicians who began their career before the war (Cusenza 2019: 3). of course, the events of 2011, and the subsequent separation from their homeland, the need for adaptation, the mood and position of the host society as well as other hardships and difficulties they encountered along the way, had an impact on their work.

However, another phenomenon is more curious - the political conflict and the subsequent migration of Syrian citizens made it possible to create a new class of emerging artists, musicians and other representatives of the artistic environment. Former medical students, engineers, school teachers and shopkeepers - many of them are now photographers, artists, singers, and writers. The representatives of this emerging class explain the change in priorities with the following aspects:

- harsh censorship of self-expression in arts and the control by the authorities and regulatory bodies in their homeland, the impossibility and unwillingness to confront and conflict with them;

- the lack of opportunities for a full-fledged education in the field of arts in Syria, inability to take place as a professional artist / musician / writer;

- the key role of transformations they went through and their desire to express their opinion and share their ideas, tell about their fears, feelings and emotions; 
- difficulties in communication with the representatives of the "host" society, the lack of required language skills that made them search for alternative ways to communicate;

- female artists often say that their role was underestimated in the homeland, where they could not do what they really wanted (arts).

When analyzing the areas of arts, which in recent years have received a number of artists from Syria, we came to the conclusion that mainly they represent the visual arts (graphics, painting, sculpture), musical art (vocal performance, instrumental music), literature (prose and poetry), photography and cinema. Syrian artists and photographers become successful, and it is not a surprising fact - for the public the visual image is easier to perceive, public is more responsive (Abbas 2014).

\section{The Political Factor and the National Identity Issue}

As a part of the analysis of the art works by Syrian artists, we often tried to find convincing evidence that would allow us to answer the question of how "politicized" the art of respondents is, and whether they try to emphasize their belonging to the Syrian nation in the process of self-expression. In a study by Cristina Cusenza, who conducted a number of extended interviews with artists from Syria, now living and working in London, she noted the following paradox: Syrian artists connect the motives of their work with Syria, its traditions, national characteristics and visual images, but at the same time, they deny that their work is politically charged, emphasizing that they are completely apolitical. Those artists who were subjected to ideological persecution in their homeland, became victims of censorship, received real prison sentences for trying to express themselves, agree that such a confrontation undoubtedly affected their formation as artists, but they still deny that the plots of their paintings are related to their political views (Cusenza 2019: 15).

To illustrate it in a clear way, we would like to give an example of Hassan, an artist who became one of the respondents in our study, originally from Latakia (Syria), but now living in Barcelona (Spain) for more than 4 years. During the interview he claims: in his work he tries to preserve the charm of Syria, using the color palette of its nature represented by the blue-green tint of the Mediterranean Sea in the suburbs of Lata$\mathrm{kia}$, the beige and yellowish color of the buildings and the deep green color of the trees. At the same time he admits that in recent years Spain has influenced him and his work a lot: he began using red color more often, his work became bolder, more relaxed, which is obvious if you, for example, have a look at the images of women who sometimes appear half-naked in his paintings - it was impossible a few years ago. He also suggests that art studies helped him to understand better what techniques can be used be able to image what arises in his mind. He also connects his formation as an artist and transformations of his techniques with the influence of the works by Pablo Picasso and Salvador Dali. 


\section{SM̂PP}

Such integration of new life experience as a plot for artistic self-realization is not uncommon. On the official Syria.Art page on Facebook, where the works of artists from Syria are presented, it is very common: for example, in Khaled Takreti's "Hommage à Notre Dame de Paris" (Tribute to Notre-Dame de Paris Cathedral) the artist transmitted all the pain of the French nation that almost lost one of the key symbols of the country in a fire - such an understandable feeling that every Syrian experienced when the once beautiful streets of their native cities were destroyed by bombing.

\section{Themes and Narratives of the Syrian Visual Art}

124 paintings by Syrian visual artists who live and work in the EU countries, were analyzed as a part of the research. The aim was to identify the major thematic lines:

- trauma caused by losing home: a thematic line based on depicting native places, familiar streets, people who have remained at home or passed away;

- self-identification as a representative of the Syrian nation: the images of the elements of their national culture associated with folklore and traditions - arrangement of the traditional Syrian house, the image of a females wearing national costumes, national dishes on the table, elements of Arabic calligraphy and etc.;

- "unfriendliness" of the new environment: dramatic plots of "loneliness in the crowd", "little man", "man without a face", etc.

- the concept of "homelessness" and "unrootedness" - eclectic images, mixed elements and themes, combined techniques.

We used comments and descriptions given by the artists themselves in order to interpret the thematic lines and plots depicted by them correctly.

As a part of the final stage of the study, we addressed the respondents from a group represented by Syrian people (now living in Spain, Germany and Russia), among them - students in various fields (16), architects (2), doctors (2), housewife (1), unemployed (4), engineers (2), university professors (3). In the first part of the interview each of the respondents was asked 3 questions:

- What is the main theme of the painting?

- Is it an important topic for you? Does it provoke any emotions?

- Will the topic raised by the artist be understandable for the members of the "host" society? Will it resonates with them?

The results of the interview were quite impressive: $87.5 \%$ respondents correctly determined the main theme, accompanying their answers with comments that the topic is close to them, and that the artist's idea resonates with them, but they are not sure that all the problems raised by Syrian artists find a response from the representatives of the "host" society. The vast majority of respondents suggested that for the latter, the plots related to the external consequences of the war (destruction 
of cities, loss of life, chaos) and the specifics of Syrian culture (recognition of national ornaments, elements of Arabic calligraphy, national dishes and musical instruments) will be most understandable, while for themselves it is more emotional to see paintings depicting the idea of being rejected by the society, loneliness, homesickness:

Selma (24) notes that when she's looking at Mohammad Zaza's painting "Altawaf in a Parallel Universe" (2015), she mainly gets the feeling of loneliness and despair: "These circles of people and things remind me of my day by day life full of hardships, new places and new people with the only thing I tried to keep in mind - our house in Syria which now seems as it never existed. I promised myself that I'll never forget it. The day I will I will stop being Syrian which I am proud to be".

Muneer (54) says that he was impressed by the paintings by Mohamad Khayta, a young artist from Damascus, who moved from Syria to Lebanon in 2012 and whose art is a result of years of displacement: "When I'm looking at Mohamad Khayta's paintings, I see clearly that they were painted by a Syrian artist, who loves his country as much as I do. It is hard to explain but the colors he picks, the forms and ornaments, integrated into his art, are truly Syrian, I can feel his longing for home and his devotion to Syrian traditional art".

Bushra (37) admits that the painting by Johnny Semaan "Away from the city I choose my patience" (2017) cuts to her heart: "6 people sitting on the poles, just waiting; some of them are connected by a thin thread, some of them are not. They are like us, Syrians, forced to live on all 6 continents of the planet, some of us are still having this connection with our home, but some have already lost it, so painful".

\section{Conclusions}

The study allowed to draw the following conclusions:

- within the context of the migration crisis the work of immigrants from Syria serves not only as a mediator between the representatives of the Syrian nation and the members of the "host" society, but also becomes a social request to be accepted and become a part of the "host" culture;

- the works of migrants from Syria, as well as of migrants from other countries, are shaping the alternative public sphere. The consumers of this sphere are not only "them" - migrants, but also "us" - the representatives of the "host" society, and the demand for these forms of artistic expression is only growing. All that let us suggest that the art of migrants plays the role of "lingua franca" - a language in its non-verbal form that can help people establish communication and understand each other better;

- within the analysis of visual art products (124 paintings selected by the continuous sampling method), we came to the conclusion that the main thematic 


\section{SM̂PP}

lines and problems that artists raise in their work are: psychological trauma caused by the need to leave their home; the problem of identifying oneself as a representative of the Syrian nation, identifying oneself with the Syrian people, traditions and customs; the lack of communication with representatives of the "host" society, lack of understanding and acceptance, hostility and conflict environment; the problem of self-identification, abandoning one's roots;

- the experimental part of the study that consisted of a number of interviews with respondents from Syria, let us draw the conclusion that in more than $87 \%$ of cases the respondents correctly correlated what they saw in the paintings with the problem or theme raised by the author, which indicates the coincidence of their vision as a whole and the presence of key elements characterizing the perception of immigrants from Syria of the surrounding reality.

The present conclusions are intermediate, and the study itself has a wide range of possibilities for more profound and continuous analysis. The present study is only the first attempt to analyze the above-mentioned issue. The topic itself is promising and creates a research niche for further analysis with the aim (amongst other things) to expand the sample of countries whose experience can be included in the research base, increase the number of respondents, shaping respondent groups in accordance with clearly defined criteria, determine art objects selection criteria and initiate a separate study for each art form (painting, photography, cinema, etc.). The analysis of non-visual art, as a form of self-expression through musical art that creates a wider range of associations, develops the basis for joint research with psychologists, music experts and musicians, as well as determines the unconditional novelty and relevance of the study. Taking all the aforesaid into consideration, it is possible to potentially determine the following research trajectories, as:

- we observe a huge potential for a large-scale study, including numerous extended interviews with representatives of the artistic environment - migrants from Syria;

- a study devoted to the analysis of other forms of artistic expression - music, literature, cinema, etc. can be of a particular interests;

- one of the further stages of the study could become a comparative analysis with the aim to compare how ways and forms of artistic expression of Syrian artists have changed since the beginning of the political crisis;

- it would also be of interest to understand to what extent the art of immigrants from Syria is commercially successful, and whether the "market of Syrian art" has been formed during all the period;

- how the new generation of Syrians who was born and raised in the EU perceive the artistic expression of Syrian descendants;

- how the Syrian art from the EU is perceived by the Syrian nation. 


\section{References}

Abbas H. (2014), Between the cultures of sectarianism and citizenship, in: Halasa M., Omareen Z., and Nawara Mahfoud N. (eds.), Syria Speaks: Art and Culture from the Frontline, London: Saqi.

Becker C. (2005), Strategies of Power Consolidation in Syria under Bashar al-Asad: Modernizing Control over Resources, "The Arab Studies Journal", no. 13, p. 65-91.

Boëx C. (2011), The end of the state monopoly over culture: Toward the commodification of cultural and artistic production, "Middle East Critique", no. 20, pp. 139-55.

Buchakjian G. (2012), War and Other Impossible Possibilities: Thoughts on Arab History and Contemporary Art, Beirut Alarm Editions.

Cooke M. (2016), Dancing in Damascus: Creativity, Resilience, and the Syrian Revolution, Abingdon: Taylor \& Francis.

Cusenza C. (2019), Artists from Syria in the International Artworld: Mediators of a Universal Humanism, Special Issue "Arts and Refugees: Multidisciplinary Perspectives" Vol. 8, Switzerland.

Foley S. (2013), When life imitates art: The Arab Spring, the Middle East, and the modern world. Alternatives, "Turkish Journal of International Relations", no. 12 pp. 32-46.

Gregory J.N. (1989), Dust Bowl Legacies: The Okie Impact on California, 1939-1989, "California History", Vol. 8, no. 3, pp. 74-85.

Griswold E. (2018), Mapping the Journeys of Syria's artists: The New Yorker. Available online: https://www.newyorker.com/culture/culture-desk/mapping-the-journeys-of-syrias-artists (accessed on October 29, 2019).

Habermas J. (1991), The Structural Transformation of the Public Sphere: An Inquiry into a category of Bourgeois Society, Cambridge, Mass.: MIT Press, pp. 175-177.

Holmes S.M., Castañeda H. (2016), Representing the "European refugee crisis" in Germany and beyond: Deservingness and difference, life and death, "American Ethnologist" no. 43, pp. 12-24.

Isabelle R., Saitta E. (2012), Mediating Cultural Diversity in a Globalized Public Space, Basingstoke: Palgrave Macmillan.

Kaur R., Dave-Mukherji P. (2014), Arts and Aesthetics in a Globalising World, London: Bloomsbury Publishing.

Малохов В., Олимова С., Марк Симон М., (2018), Творчество мигрантов как проблема социологии культуры: выходцы из Таджикистана в России, Неприкосновенный запас, no. 3, pp. 30-54.

Mackinlay J. (2003), Artists and war, "The RUSI Journal", no. 148, pp. 20-23.

Takieddine Z. (2011), Arab Art in a Changing World, "Contemporary Practices", no. 8, pp. 54-61. Winegar J. (2008), The humanity game: Art, Islam, and the war on terror, "Anthropological Quarterly", no. 8, pp. 651-68.

Zinn H. (2011), Artists in Times of War, New York: Seven Stories Press. 